\title{
Cultural/Community Mentoring with Maori and Pacific Electrical Apprentices
}

\author{
CHRIS HOLLAND
}

\begin{abstract}
New Zealand government policy documents over the last decade have committed to supporting Maori and Pasifika learners, yet still today there is little real support in place for learners in apprenticeships. There is even less support in place that acknowledges the cultural dimension of learning in the workplace. This paper discusses the establishment and review of a development project which sets out to provide culturally supportive mentoring for Maori and Pasifika apprentices. The project sought to do this by engaging experienced Maori and Pasifika tradesmen who were located in the local communities of their learners.
\end{abstract}

\section{Introduction}

This paper discusses research and development in apprentice mentoring in New Zealand, in particular the mentoring of Maori and Pasifika apprentices.

Recent New Zealand tertiary reports observe that significant numbers of enrolled apprentices, particularly Maori and Pasifika learners, have been failing to complete their qualifications (Tertiary Education Commission 2008), and these observations are backed by government statistics (Mahoney 2010) and qualitative case studies (Holland 2008, 2009, 2010). Arguments have existed in government policy documents for over a decade about the need to turn around low qualifications for apprentices - particularly Maori and Pasifika - in order to improve employment opportunities and outcomes, business competitiveness and national productivity (Ministry of Education 2001).

As the above mentioned government documents show, embedding literacy and numeracy delivery and assessment in vocational education, and targeting Maori and Pasifika learners, has been seen to be the primary solution to low achievement over the last decade. Yet more recently, strategy documents are exploring the effectiveness of existing non-teaching support for apprentices, and strategies to improve support (Kopu 2010). This reflects a broadening of perspective from simply making chunks of learning more accessible to learners, to understanding the part that relationships and culture play in learning. 
While tertiary education agencies have been carving up learning into graded unit standards, embedding literacy and numeracy into programs and materials, and assessing apprentices on-line at enrolment, employers and management texts tell us that relationships are the key. That is, who you are, how you engage with people, how you fit in, how you contribute your skills to the team (see, for instance Covey 1990, 2000, Peters 2010). Identity and relationships do seem to be crucial to job retention, learning and progression for workers at all levels. Research indicates that cultural identity and the ability to identify with the culture of the workplace are important factors in apprentice success (Billett 2003, Billet and Somerville 2004, Holland 2011). Where such identification is weak, relationships at work - and therefore success with learning - may be at risk (Holland 2009). This paper discusses relational mentoring (Clutterback and Lane 2004) in which culture plays a significant part. Since 2008, a small number of development projects have taken place with the co-operation of the Industry Training Federation (ITF). Industry Training Organisations (ITOs) have been supported to establish mentor training and mentoring within their industries, and that mentoring has been monitored and reviewed. Participating ITOs have included Glazing and Joinery, Fire and Rescue Services, Hairdressing, Electrotechnology and Hospitality. Mentoring guidelines have been produced and existing mentoring systems have been strengthened (see:

www.itf.org.nz/assets/Publications/Literacy-Publications/ITF-MentoringGuide-Aug09.pdf).

A range of approaches have been implemented in companies to improve apprentice learning support. Two glass companies have established weekly mentoring sessions with young apprentices led by female administrators. The apprentices were completing distance learning modules, and the administrators were able to assist with time management and to provide the literacy and numeracy support they needed to complete the modules. The Hairdressing ITO has successfully instituted trainers in every salon, and established professional development for these trainers that raises their skills in mentoring their young apprentices. In the volunteer fire services, brigade members who have been in the service for little more than a year have demonstrated that they can support new members to complete their learning modules (one-up mentoring). Recently in the hospitality industry, companies and non-profit organisations have been supported to establish mentoring and mentors have so far taken part in initial training workshops. Mentoring in the electro-technology industry has focused on Maori and Pasifika apprentices.

In 2011 the Electro-technology ITO (ETITO) introduced a groundbreaking approach to mentoring. Maori managers in the organisation understood that Maori and Pasifika apprentices would need 
cultural support as well as support with issues such as literacy and numeracy, to complete their apprenticeships and study. Their belief is backed up in the literature. Durie (2001) writes that for Maori to be successful in tertiary studies, they need to acknowledge their Maori identity and be nurtured in their Maori values. Hook, Waaka and Raumati (2007) suggest that Maori can become disenchanted when the European workplace does not acknowledge important principles and connections such as whanaungatanga (relationship/togetherness/collectivity), the preservation of mana, mahakitanga (humility) and Wairuatanga (spirituality). Smith (1999) contends that these Maori cultural values are underpinned by concepts such as reciprocity, nurture, support, group responsibility, and sharing. Hook, Waaka and Raumati (2007) and Ratima and Grant (2007) add that collective learning is important for Maori learners' success.

\section{Policy context}

Apprentice mentoring is not yet recognised by the New Zealand government as a key strategy for improving job retention and qualification completions. Functional literacy and numeracy assessment and delivery remain a key focus of government agencies concerned with improving industry productivity through workplace learning (see:

www.tec.govt.nz/Funding/Fund-finder/Intensive-Literacy-andNumeracy/). Since about 2005 'embedded literacy' in vocational course materials and delivery has been required (see:

www.tec.govt.nz/Documents/Reports\%20and\%20other\%20documents/lit eracy-numeracy-ITO-embedded-literacy-numeracy-supportinginformation-and-requirements.pdf).Text books and tutor guides have been re-written, and tutors have attended workshops and practised embedded delivery. In addition, a national literacy assessment is required of new apprentices (see: www.tec.govt.nz/Resource-Centre/Softwaretools/Literacy-and-Numeracy-for-Adults-Assessment-Tool/). Apprentices undertake the on-line assessment at the start of their apprenticeship and may be referred to literacy and numeracy specialist support if they do not score well.

Many young people taking up apprenticeships do not score well on these assessments, for a variety of reasons. For example, they tend to enter the trades because their strengths and interests involve working out concrete, practical problems and engaging in hands-on tasks in their day-to-day world, and they have little or no interest in school-like literacies though a great interest in understanding the literacies of their chosen trade (Holland 2011). Another reason is culture, as discussed by other authors cited in this paper (e.g. Durie, Smith, Hook, Waaka and Raumati, and Ratima and Grant). 
According to government statistics, literacy appears to be a more of a barrier for Maori and Pasifika in schools and therefore for youth enrolling in apprenticeships. The Literacy, Language and Numeracy Action Plan 2008-2012 (Tertiary Education Commission 2008) states that Maori and Pacific youth tend to perform less well than Pakeha New Zealanders in standardised adult literacy assessments. The strategy states a strong commitment to supporting Maori and Pacific Island communities in particular. Yet there is little evidence of the incorporation of particular Maori and Pacific cultural approaches to learning as recommended by Maori academics.

A Modern Apprenticeship (MA) program was introduced by the New Zealand Government in 2000 in order to rebuild trades training towards nationally-recognised qualifications for young people in New Zealand. Yet the number of Maori and Pacific apprentices in most trades continues to be low in comparison with the population as a whole, and completions are comparatively low. The latest available figures on apprentice completions (Mahoney 2009) are as follows: of 529 enrolled Maori apprentices in 2003, $21 \%$ completed, and of only 63 enrolled Pasifika apprentices in 2003, 13\% completed. In the electro-technology industry, completion rates for all apprentices were 55\%. There are no separate statistics for Maori and Pasifika completions in this industry.

Shortly after the introduction of MAs, Modern Apprenticeship Coordinators (MACs) were put in place to support apprentices by engaging in meetings with them approximately every three months. A 2010 Mayors Taskforce report stated that the success of the MAC program was linked to 'the ability of the MAC to provide: quality, meaningful and effective interventions at key points in the apprentices' learning and employment' (Kopu 2010). Kopu elaborates that completion rates are linked to the delivery of support and that the culture of industry towards workplace diversity needs to be challenged. Other research (Holland 2009, 2010) indicates that the three-monthly meetings the MACs were paid to undertake were too infrequent to be effective and also that over time, many MACs came to have a joint role of co-ordinator/assessor. This joint role creates a conflict between power and support in the relationship, impacting on the level of trust that can be developed.

\section{Relational Mentoring}

Current literature on mentoring recognises that mentors need to build a trust relationship through empathy, and the focus has been gradually shifting from a traditional paternalistic model to a relational model (Clutterback and Lane 2004). Under a relational mentoring model, the worker is regarded as a valued equal who happens to have specific support needs. The relationship is one of generalised supportive friendship. Ragins 
and Verbos (2006) believe that relational mentoring is the highest quality mentoring state. They attribute to relational mentoring the ability to develop empathic, empowering processes that create personal growth, development and enrichment for both mentors and learners. In relational mentoring the agenda is mutually driven; there are specific development areas and goals and a clear purpose; it is non-discriminatory and discussions are non-reported (Clutterback and Lane 2004, Connor and Pakora 2007). In the best examples of relational mentoring, power and authority are irrelevant. Face to face meetings are regular, scheduled, and structured to include specific and mutually agreed development areas and goals. It was this model of mentoring that influenced the Electro-technology Industry Training Organisation's mentoring pilot.

\section{ETITO Mentoring pilot - a cultural / community model}

Late in 2010 the Electro-technology Industry Training Organisation (ETITO) began planning a pilot mentoring project. The organisation was aware that a low number of Maori and Pacific people apply for apprenticeships in their industry, and also that the drop-out rate for those whose applications are successful, is high. In January 2011, ETITO established training for mentors and a pilot mentoring scheme for apprentices, using a cultural/community model that was more relational than traditional in its approach. It also commissioned an evaluation project to run alongside the work.

ETITO personnel were aware that the industry employed relatively few Maori and Pasifika electricians and that it would be hard to find mentors who could support apprentices with cultural issues. They looked then to the apprentices' local communities for self-employed Maori and Pasifika electricians or those working in the building industry generally. Mentors were chosen firstly because they shared a common cultural background with the apprentices, secondly because of their proximity to the apprentices' local communities, and only thirdly because of their specific electrical trade knowledge. It was important that the mentors were not in a position to exercise power over the apprentices - except in one instance, they were not supervisors or bosses, but experienced trades people who cared for the wellbeing of young Maori and Pacific apprentices. At least two mentors were from allied trades such as plumbing and building.

The mentor group were trained over two days, three months apart. The central messages of the training were that mentoring should have clear goals, trust is vital, mentoring should support apprentices at regular face to face meetings in order to help with learning issues, and mentors should be prepared to act as advocates. Mentors also learned that they were not expected to teach, but simply to share their experience and knowledge of 
how to get on in the workplace, manage documentation and complete the required study. Some mentors found the work demanding. A month after the induction weekend, two mentors withdrew - one because of an injury and the other because of other commitments. Two new mentors were introduced. One was a Maori tradesman and the other was a Pakeha manager from ETITO. The latter choice was a risk because the mentor was in a position of authority over his apprentice.

The cultural/community aspect of the mentoring program was innovative. ETITO managers believed that drawing Maori and Pacific mentors from the local community would help to build apprentice trust in the mentor, and would give mentor and learner greater access to each other. The mentors were paid a small sum and were required to visit apprentices face to face once a month and to contact them regularly by text, phone or email. The electrical apprentices in each community attended evening classes at the local technical college in their locality. Ten were chosen for the pilot - all were young men.

The apprentices on the scheme were introduced to all the ETITO selected mentors at a three day launch/induction event at a country retreat south of Auckland. This was a collective exercise, where the new apprentices were supported by older Pacific and Maori management and mentors, and encouraged to support each other. While the apprentices worked hard over the three days, relationships were also being built with each other and with managers through communal eating and lots of socialising. Each apprentice was given the opportunity to choose his own mentor at end of the weekend through a five minute rotating discussion. Apprentices were then placed with a large electrical service company working with a range of small contracting businesses.

\section{The Research project}

The monitoring and review of the pilot program was commissioned by ETITO in February 2011 and tracked the impact that mentoring was having on both the learners and mentors over a year. We wanted to test how a uniquely supportive relational mentoring environment for Maori and Pacific apprentices might make a difference to apprentices' work relationships, negotiation of the new workplace culture, and learning and development. Research participants included ETITO management, the mentors' group, the Modern Apprenticeship co-ordinator/assessor, and members of the apprentice group.

A qualitative, participatory action research methodology drawing on Maori research methodologies (Smith 1999) was used, where trust relationships were built between the researcher and all participants through meetings, formal interviews, observations and social gatherings. Gatherings 
in the first six months included the induction itself at the country retreat, McDonald's, a barbeque and a traditional Maori meal at a Marae ${ }^{1}$. In addition, a private 'electrical apprentices' group was set up on a social network site - Facebook. Six apprentices joined. Four of these engaged in research related conversation for approximately two months. However, texting and face-to-face meetings proved to be a more ready and reliable form of communication. Some quotes from observations, interviews and focus groups, social gatherings and the electrical apprentices group on Facebook are presented in the following section.

\section{The apprentice experience of mentoring}

Apprentices talked about feeling privileged and grateful to be selected for the program. They felt respected by the mentors, recognised culturally, supported and championed. They trusted the mentors. The apprentices also recognised that this special opportunity had implications not only for themselves but for future generations of Maori and Pacific apprentices. Two examples of their comments are as follows:

I look at this opportunity with the back of mind of say who knows, maybe this will be the first and the last opportunity for Maori Pacific and I take it.

Sometimes it brings me to tears because that's what I want to do in the future. I want somebody to trust me and if I move on and be successful I want to mentor. I like paving the way. It's a good feeling.

Apprentices and mentors usually met away from the workplace, such as in cafes or McDonald's. McManus and Russell (2007: 294), writing about peer mentoring relationships, note that 'Repeatedly, researchers have suggested that individuals who have multiple sources of support fare better than those who do not'. There was evidence that mentors in this project were swapping notes about their proteges in ways that added value to the support that was being offered. This sharing of information was a means of mentors gaining support from each other. Two mentors worked together regularly as they each had two apprentices to mentor. Collaborating in a group of six improved the support they could offer.

A disturbing trend was the increasing expectation by mentors that the apprentices should call the mentor (rather than the mentor calling the apprentice). The mentors concerned felt that this showed the apprentices

1 a traditional Maori tribal meeting place, originally one in the open air, now frequently a purpose-built building 
were taking responsibility. Indeed, some apprentices, while very happy to be part of the mentor program, had asserted that they did not need help right now, and would say so if they did. The difficulty was that while this approach may have built independence in more confident apprentices, others felt less supported. Waiting for the apprentice to call also meant that time between contact was more likely to be extended beyond once a month, and this risked a stretch in the very fragile thread of trust that was being built between mentor and apprentice. One apprentice experienced difficulties which were not picked up by the mentor until it was too late and he lost his job.

For most of these apprentices, the needs of the family - and church came first, and life decisions were strongly influenced by both. Pacific apprentices' first responsibility was to give earnings to the family in New Zealand, so that they could send it to family outside of New Zealand or to give a percentage to the church. Because of the requirement to distribute earnings in this way, many families needed their young people to be earning high wages, and therefore there was sometimes parental resistance to apprenticeships, where only the minimum wage is offered in the first year.

Hook, Waaka and Raumati (2007:5) comment that within a Maori framework mentoring is not restricted to individuals and can extend to whole whanau (close and extended family). The Pakeha mentor had learned that his apprentice's family was taking his apprentice earnings, leaving him no money for public transport, lunch, and learning expenses (he needed to get his driver's licence). The mentor did not feel confident to visit the family on his own, so he called on another mentor and together they talked with the family, providing information about their son's apprenticeship, and eventually finding a solution that suited the family as well as the apprentice.

Doherty and Dreher (2007) suggest that a mentor can bring about greater visibility of the trainee in the workplace, and can make decisionmakers more aware of the trainee's potential. The greatest successes that the mentors have had with the apprentices tend to be in terms of breaking down attitudinal barriers. The mentors commented:

[The electrical service company] is a prime example 'cos at the end of the day they didn't want to take them on but all the tutors that supported the process at the time said these are the best young men we've ever had.

Jay came back to me and he said ...'We've got a big job at the prison but these guys would feel at home there', just a stereotype we've got to deal with.

Lack of cultural capital in terms of the workplace culture is a further barrier - there are few role models in Maori or Pacific families who can show new young apprentices what to expect. In only four cases, members of 
apprentices' families had worked in a trade (one of these was the electrical trade).

The mentors helped in very practical ways to overcome these and other barriers, often working together to resolve an issue. One apprentice was helped to get his driver's licence and to keep his placement with the electrical service company while he was immobile. Another mentor helped an apprentice to work through his debt crisis. Others helped their apprentices to negotiate with polytechnic course tutors where the apprentices had not completed the pre-course work required before entering the apprenticeship. Yet another mentor was able to support an apprentice when he was considering leaving and this resulted in him continuing much more enthusiastically with his apprenticeship. The apprentice commented:

... the stuff we talked about, all I can say is he really changed my perspective on this apprenticeship in a positive way ... made me look at the big picture ... changed my attitude ... now things are great.

The mentors had earned the trust of their learners. They understood their apprentices' cultural values such as reciprocity and the importance of family, and how these impacted on their performance. They had acted as powerful advocates for their apprentices.

Although the mentors have made an important difference to apprentices' ability to learn in the job, more professional development is needed. There is still work to be done in terms of structuring mentoring sessions, setting goals, reviewing progress from session to session, and in identifying supporting apprentices with tasks involving literacy and numeracy. For instance, an area where literacy and numeracy related support could be offered is in understanding log books and completing log book entries. The books the apprentices had been issued with comprised a front section where apprentices were required to record the jobs they undertook each day, and a back section where they were to identify the relevant unit standard and map it to the job. Several apprentices demonstrated or admitted that they did not understand how to do this. Our examination of the log books revealed that the unit standards pages took up almost half of the book, and that the apprentices had to read through these standards in order to find the one that most closely matched the job they had just completed. It was slow and laborious - the qualifications jargon was difficult for first year apprentices. Most guessed at the matching unit standard number, and getting it wrong was common.

Overall, the pilot was a success. The most convincing results for ETITO were that of the ten apprentices, only one apprentice withdrew (to go on to further and higher education) and only one lost his position with 
the electrical company (partly due to a break in mentoring). This reflects an $80 \%$ success rate in terms of job retention. While it is too early to assess the impact of mentoring on qualification completions, indications on the retention rate are that completions will be higher than current rates for Maori and Pasifika and for all electrical apprentices.

\section{Summary}

We have learned from previous research how learning is being supported in the workplace. We have learned from this research, some of the strengths and weaknesses of cultural/community mentor support. We know that the mentors understand Maori and Pacific cultural values such as reciprocity, nurture, tribal support, group responsibility, and sharing and support The mentors have acknowledged their own, and their learners' Maori and Pacific identities and have nurtured apprentices in the appropriate values.

We discovered that the apprentices face multiple barriers to success in the chosen field. These include institutional, financial and social capital barriers. We explored the extent to which some of the characteristics of relational mentoring were evidenced in this cultural/community mentoring program. These included making contact and showing equal respect, recognising cultural diversity and learner strengths in language use, understanding how important trust is in relation to supporting learning, identifying specific development areas and practising advocacy.

Have mentors made a significant difference to apprentices' formal learning results? Not really, but that was not the focus of the pilot, which was to provide support that enabled learners simply to continue with and complete their apprenticeship and study. As mentors develop their skills they will increasingly be able to work with their apprentices to, for instance, identify literacy issues with documents and fine tune and monitor progress towards apprentices' learning goals. Without goals against which progress can be checked, the structure of engagement between each party and the strength of the relationship may start to unravel.

The impact that mentoring has on these young learners reminds us that human connection is central to the learning process. We know that mentoring can re-inspire an enthusiasm for learning and success. We also know that the cultural/community mentor model, with its special focus on Maori and Pasifika values and needs, is successful for such apprentices. Not only successful, but necessary. For low paid learners frequently blamed for poor productivity and performance at national and local levels, we need to keep improving mentoring models that build apprentices' confidence in themselves and show what they can contribute. We need to establish and develop first-year apprentice mentoring across a wider range of industries, to 
track the impact on apprentices and to monitor and review progress. This will provide evidence of what still needs to be done to ensure the ongoing improvement and success of apprentice mentoring.

Whangia ka tupu, ka puawai. That which is nurtured, blossoms and grows.

\section{References}

Billett, Stephen (2003) Workplace Mentors: Demands and benefits, fournal of Workplace Learning, vol 15, no 3, pp 105-113.

Billett, Stephen and Somerville, Margaret (2004) Transformations at Work: Identity and learning, Studies in Continuing Education, vol 26, no 2, pp 309-326.

Clutterbuck, David and Lane, Gill, eds (2004) The Situational Mentor: An international review of competencies and capabilities in mentoring, Gower, Aldershot.

Connor, Mary and Pakora, Julia (2007) Coaching and Mentoring at Work: Developing effective practice, Open University Press, Berkshire.

Govey, Stephen R (1990) Principle-Centered Leadership, Simon \& Schuster, New York.

Covey, Stephen R (2000) The 7 Habits of Highly Effective People, Perseus Books Group, New York.

Dougherty, Thomas W and Dreher, Geroge F (2007) Mentoring and Career Outcomes: Conceptual and methodological issues in an emerging literature, in Ragins, BR and Kram, K, The Handbook of Mentoring at Work, Sage, California, pp 51-94.

Durie, Mason (2001) Cultural Competence and Medical Practice in New Zealand, paper presented at Australian and New Zealand Boards and Council Conference, Wellington.

Holland, Chris (2008) Under No Illusion: A research report into vocational tutor learning and practice in embedded literacy, report prepared for the Hairdressing Industry Training Organisation and the Tertiary Education Commission, Tertiary Education Commission, Wellington.

Holland, Chris (2009).On and Off the fob: Learning experiences, connections and implications for $L L N$, report for the Joinery and Glass Industry Training Organisation, Joinery Industry Training Organisation, Wellington.

Holland, Chris (2010) Mentoring Survey for Volunteers in Volunteer and Combined Brigades, Fire and Rescue Services Industry Training Organisation, Wellington.

Holland, Chris (2011) Someone Like Us: Trades identities and support for workplace learning, Literacy and Numeracy Studies, vol 19, no 1, pp 1934. 
Hook, G Raumati, Waaka, Tū and Raumati, L Parehaereone (2007) Mentoring Maori Within a Pakeha Framework, MAI On-line Review, vol 3 no 1. http://ojs.review.mai.ac.nz/index.php/MR/issue/view/8

Kopu, Bry (2010) Modern Apprenticeships: An examination of the current challenges and opportunities facing the Modern Apprenticeship Programme in New Zealand, BMK Group and Mayors Taskforce for Jobs, New Zealand.

McManus, Stacy E and Russell, Joyce EA (2007) Peer Mentoring Relationships, in Ragins, BR and Kram, K, The Handbook of Mentoring at Work, Sage, California, pp 273-298.

Mahoney, Paul (2009) Modern apprenticeships - Completion analysis, Ministry of Education, Tertiary Sector Performance Analysis and Reporting Wellington, New Zealand.

Ministry of Education (2001) More Than Words: The New Zealand adult literacy strategy. Ministry of Education, Wellington.

Peters, Tom (2010) The Little Big Things: 163 Ways to Pursue Excellence. Harper Collins, New York.

Ragins, Belle R and Verbos, Amy (2006) Positive Relationships in Action: Relational mentoring and mentoring schemas in the workplace, in Dutton, JE, and Ragins, BR, eds, Building a Theoretical and Research Foundation, California, Sage, pp 91-115.

Ratima, Matiu and Grant, Barbara (2007) Thinking About Differences Across and Within Mentoring, MAI Review, 3, Peer commentary 1, pp $1-5$.

Smith, Linda T (1999) Decolonizing Methodologies: Research and indigenous peoples, Zed, London.

Tertiary Education Commission (2008) Literacy Language and Numeracy Action Plan 2008-2012, TEC, Wellington. 